Article

\title{
Removal of $17 \beta$-Estradiol by Activated Charcoal Supported Titanate Nanotubes (TNTs@AC) through Initial Adsorption and Subsequent Photo-Degradation: Intermediates, DFT calculation, and Mechanisms
}

\author{
Taobo Huang ${ }^{1}$, Baozhu Pan ${ }^{1}$, Haodong Ji ${ }^{2, *}$ and Wen Liu ${ }^{2}(1)$ \\ 1 State Key Laboratory of Eco-Hydraulics in Northwest Arid Region, Xi'an University of Technology, \\ Xi'an 710048, China; taobo.huang@foxmail.com (T.H.); zhuzipan@xaut.edu.cn (B.P.) \\ 2 College of Environmental Sciences and Engineering, Peking University, The Key Laboratory of Water and \\ Sediment Sciences, Ministry of Education, Beijing 100871, China; wen.liu@pku.edu.cn \\ * Correspondence: jihaodong@pku.edu.cn; Tel.: +86-010-62744799
}

Received: 30 June 2020; Accepted: 23 July 2020; Published: 26 July 2020

\begin{abstract}
A low-cost composite of activated charcoal supported titanate nanotubes (TNTs@AC) was developed via the facile hydrothermal method to remove the $17 \beta$-estradiol (E2, a model of pharmaceutical and personal care products) in water matrix by initial adsorption and subsequent photo-degradation. Characterizations indicated that the modification occurred, i.e., the titanate nanotubes would be grafted onto the activated charcoal (AC) surface, and the micro-carbon could modify the tubular structure of TNTs. E2 was rapidly adsorbed onto TNTs@AC, and the uptake reached $1.87 \mathrm{mg} / \mathrm{g}$ from the dual-mode model fitting. Subsequently, the adsorbed E2 could be degraded 99.8\% within $2 \mathrm{~h}$ under ultraviolet (UV) light irradiation. TNTs@AC was attributed with a unique hybrid structure, providing the hydrophobic effect, $\pi-\pi$ interaction, and capillary condensation for E2 adsorption, and facilitating the electron transfer and then enhancing photocatalytic ability for E2-degradation. In addition, the removal mechanism of E2 was elucidated through the density functional theory calculation. Our study is expected to provide a promising material for environmental application.
\end{abstract}

Keywords: titanate nanotubes; activated charcoal; pharmaceutical and personal care products; adsorption; advanced oxidation processes

\section{Introduction}

Recently, endocrine disrupting compounds (EDCs), as typical pharmaceutical and personal care products (PPCPs), have been widely/frequently detected in the natural water, wastewater, and sediment $[1,2]$. In addition, the negative effects of EDCs on human health and ecosystems have drawn significant attention [1,2]. Among these EDCs, 17 $\beta$-estradiol (E2) is of great concern due to its high reactivity for endocrine activity, i.e., favorable to bind with estrogen receptors [3,4]. Even at low concentration $(\mathrm{ng} / \mathrm{L}-\mu \mathrm{g} / \mathrm{L}), \mathrm{E} 2$ is still hard to be removed by conventional wastewater treatment plants due to the resistance to biodegradation, then resulting in the discharge to the natural environment [5]. Therefore, the effective approaches for the removal of E2 are urgently needed.

Considering the poor biodegradability of E2, some strategies have been applied to remove E2, such as adsorption [6], filtration [7], flocculation [8], and advanced oxidation process (AOP) [9]. Adsorption, as a promising technique, due to facile operation and low-cost [10], has been developed. Especially, activated charcoals or carbons (ACs) are the most widely used/developed conventional adsorbents in the lab or field applications due to their large-scale manufacturing, high adsorption capacity, 
and easy-regeneration [11,12] compared with other adsorbents [13-16]. In addition, for emerging organic contaminants, ACs offer higher adsorption capacity via the specific multi-pore/channel structure and $\pi-\pi$ interactions than inorganic adsorbents [12,17]. However, regeneration of organic-laden ACs may lead to the production of secondary air or water pollution through the combustion or organic solvents [15,18], which limits the application of ACs. Then, the environmental-friendly regeneration way for organic-laden ACs is necessary and can expand the application of ACs.

Photocatalysis, as the efficient advanced oxidation processes (AOPs), has been considered for the mineralization of organic contaminants [19] due to its environmental-friendly feature. Although numerous photocatalysts were developed in the last decades, $\mathrm{TiO}_{2}$ still serves as the most widely used photocatalyst in commerce [20,21]. Titanate nanotubes (TNTs), the derivatives of $\mathrm{TiO}_{2}$ via hydrothermal treatment, have been an attractive adsorbent and photocatalyst simultaneously due to large surface area, ion-exchange property, excellent separation performance, and photocatalytic ability [22-24]. However, the strong hydrophilicity of TNTs retards the uptake of hydrophobic organic pollutants in the aqueous phase, and the rapid electron-hole recombination rate of TNTs also limits the potential application [25]. Then, integrating adsorption and photocatalysis, i.e., ACs and TNTs, may have the potential application for PPCPs removal. First, the modification of ACs and TNTs may offer higher organic contaminants uptake than pristine ACs or TNTs; second, ACs as a good electron acceptor may inhibit the electron-hole recombination, then improve the photocatalytic ability of TNTs; third, easy-regeneration for materials through proposed integrating approach can avoid the use of extra chemical reagents, then prevent the secondary pollution from conventional adsorption treatment. Therefore, activated charcoal supported titanate nanotubes (TNTs@AC) are applied to remove E2 through initial adsorption and subsequent photo-degradation.

Herein, the overall goal of this study was to explore the proposed strategy, "pre-adsorption and subsequent photo-degradation" by activated charcoal supported titanate nanotubes (TNTs@AC). The specific objectives were to (1) investigate the adsorption behaviors of E2 by TNTs@AC; (2) gauge the effectiveness of photo-degradation of E2 by TNTs@AC; (3) elucidate the underlying mechanisms through the characterizations and theoretical calculations.

\section{Materials and Methods}

\subsection{Chemicals}

All analytical-grade or higher chemicals and reagents were used in this study. Activated charcoal (AC) as 20-40 mesh was acquired from Sigma-Aldrich (St. Louis, MO, USA). P25-type $\mathrm{TiO}_{2}$ nanoparticles (anatase:rutile $=80: 20$ ) from Degussa Co. (Evonik, Germany) were the precursor for TNTs. 17ß-estradiol (E2) was acquired from Sigma-Aldrich (St. Louis, MO, USA), and a $1000 \mathrm{mg} / \mathrm{L}$ stock solution was prepared by dissolving E2 in methanol. Chromatographic grade methanol, ethanol, $\mathrm{HCl}, \mathrm{NaOH}, \mathrm{HClO}_{4}$, and acetonitrile were purchased from Fisher Scientific (Fair Lawn, NJ, USA). Deionized water (DIW, $18.2 \mathrm{M} \Omega \cdot \mathrm{cm}$ ) from the Milli-Q system (Billerica, MA, USA) was used in all the experiments.

\subsection{Synthesis of TNTs@AC}

TNTs@AC was typically prepared via a facile one-step hydrothermal method from our previous study [26]. In brief, $1.2 \mathrm{~g}$ P25-type $\mathrm{TiO}_{2}$ and $2.4 \mathrm{~g}$ AC were dispersed into $10 \mathrm{~mol} / \mathrm{L} \mathrm{NaOH}$ solution (66.7 $\mathrm{mL}$ DIW), followed by the overnight stirring i.e., $12 \mathrm{~h}$ at room temperature. Then, the mixed dispersion was put into a Teflon-made reactor and heated for $72 \mathrm{~h}$ at $130{ }^{\circ} \mathrm{C}$. After cooling to room temperature, the separated black precipitates were fully washed using DIW to remove residual $\mathrm{NaOH}$ till close to neutral $\mathrm{pH}$. After oven-drying at $80^{\circ} \mathrm{C}$ for $4 \mathrm{~h}$, TNTs@AC was ready. For comparison, pristine TNTs and treated AC were synthesized via a similar procedure without AC or TNTs, respectively. 


\subsection{Experimental Methods: Adsorption Kinetic and Isotherm, Photoregeneration}

Adsorption kinetic tests were conducted in the dark using amber glass vials $(43 \mathrm{~mL}$, Teflon-lined caps) with E2 solutions ( $40 \mathrm{~mL}, 0.5$ or $1 \mathrm{mg} / \mathrm{L}, \mathrm{pH} 7.0 \pm 0.2)$. Then, the kinetic tests were triggered by adding $0.02 \mathrm{~g}$ TNTs@AC, i.e., $0.5 \mathrm{~g} / \mathrm{L}$, into the respective E2 solutions and shaken at $200 \mathrm{rpm}$. Then, each of the $1 \mathrm{~mL}$ samples was obtained at pre-designed intervals and membrane-filtered via $0.22 \mu \mathrm{m}$ polytetrafluoroethylene (PTFE) immediately. The filtrates were then analyzed for E2 concentration.

Adsorption isotherm tests were conducted in a similar fashion as for kinetics with various initial E2 concentrations $(0.05-1.5 \mathrm{mg} / \mathrm{L})$ and a fixed material dosage $(0.5 \mathrm{~g} / \mathrm{L})$ at $\mathrm{pH}$. The mixtures were equilibrated for $24 \mathrm{~h}$ under dark. For comparison, the adsorption isotherms by AC and pristine TNTs were also obtained.

The photocatalytic ability of TNTs@AC was evaluated under UV irradiation with $0.5 \mathrm{~g} / \mathrm{L}$ material and at $\mathrm{pH}$ 7.0. Upon adsorption equilibrium, the suspension was gravity-settled for $1 \mathrm{~h}$. After removing $\sim 90 \%$ supernatant, the residuals were put into a glass photoreactor with a quartz-made cover. Then, the reaction was started-up under UV irradiation $\left(1.42 \mathrm{~mW} / \mathrm{cm}^{2}, 365 \mathrm{~nm}\right)$. At predetermined times, i.e., $0,10,20,30,60,90,120 \mathrm{~min}$, the samples were collected and extracted by $20 \mathrm{~mL}$ methanol $\left(80^{\circ} \mathrm{C}\right.$ for $\left.4 \mathrm{~h}\right)$ to analyze the E2 concentration.

All experiments were conducted in duplicate. The experimental results were plotted by means of duplicates. In addition, error bars referred to relative deviation to the mean, indicating the reproducibility of data.

\subsection{Characterizations}

To investigate the morphology of TNTs@AC, the high-resolution transmission electron microscopy (HRTEM) was performed on Tecnai30 microscopy (FEI, USA) at $300 \mathrm{kV}$. To verify the crystalline phase and structure, $\mathrm{X}$-ray diffraction (XRD) was conducted on a D/max-2500 Powder X-ray diffractometer (Rigaku, Japan) with a scanning step of 0.02 at $40 \mathrm{~mA}$ and $100 \mathrm{kV}$. For zeta potentials, Nano-ZS90 Zetasizer (Malvern Instruments, UK) was applied.

\subsection{Analytical Methods}

E2 was analyzed on an Agilent 1100 liquid chromatography system (HPLC, USA) equipped with a $3.5 \mu \mathrm{m}$ SB-C18 column $(4.6 \times 150 \mathrm{~mm})$. The detector wavelength was placed at $210 \mathrm{~nm}$. The mobile phase consisted of $60 \%$ acetonitrile and $40 \%$ phosphoric acid solution $(0.085 \%$, v/v) with a $1 \mathrm{~mL} / \mathrm{min}$ flow rate, giving the detection limit of $\sim 1 \mu \mathrm{g} / \mathrm{L}$.

Photocatalytic degradation intermediates/byproducts of E2 were detected on an Agilent HP 1100 LC-MS ${ }^{n}$ Trap system (USA) with a Zorbax RX-C18 column.

\subsection{DFT Calculation Method}

All the computational calculations based on density functional theory (DFT) were conducted on the Gaussian 16 software (Version C.01, Wallingford, CT, USA) [27]. The optimization of geometry and electrostatic potential energy (ESP) of E2 were calculated at the level of B3LYP/6-31+G(d,p) [28-30]. Details on the optimized geometry structure and energy of E2 are listed in Figure S1 and Table S1 Supplementary materials of (SM). Visual molecular dynamics (VMD 1.9.1) was used to render and generate the colored iso-surface map of ESP [31,32].

\section{Results and Discussion}

\subsection{Material Characterizations}

Figure 1 displays the HRTEM images of TNTs@AC. As shown in our previous report by Liu et al. [26], neat activated charcoal was in bulk with the flat surface. TNTs exhibited hollow multilayered nanotubes with open-top structures, which have the inner diameter as $4.5 \mathrm{~nm}$ (Figure 1). 
After the hydrothermal treatment with $\mathrm{P}_{25}-\mathrm{TiO}_{2}$, the formed titanate nanotubes would be grafted onto the AC surface, as shown in Figure 1a, which is consistent with the other report [26]. In addition, the tiny portion in nanoscale of AC, i.e., micro-carbon, could modify the tubular structure of TNTs (Figure 1b), which transfers the original open-end structure of the pristine TNTs as the narrow throat.

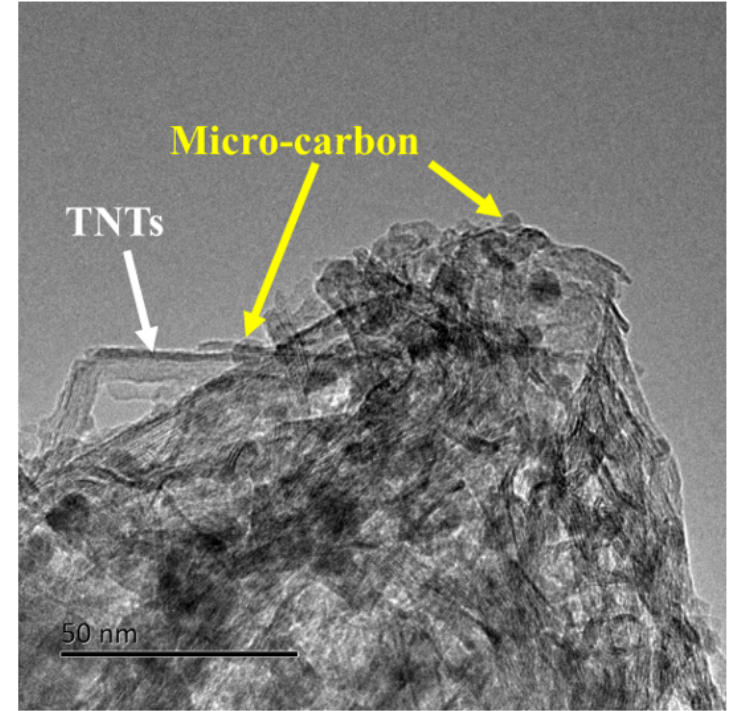

(a)

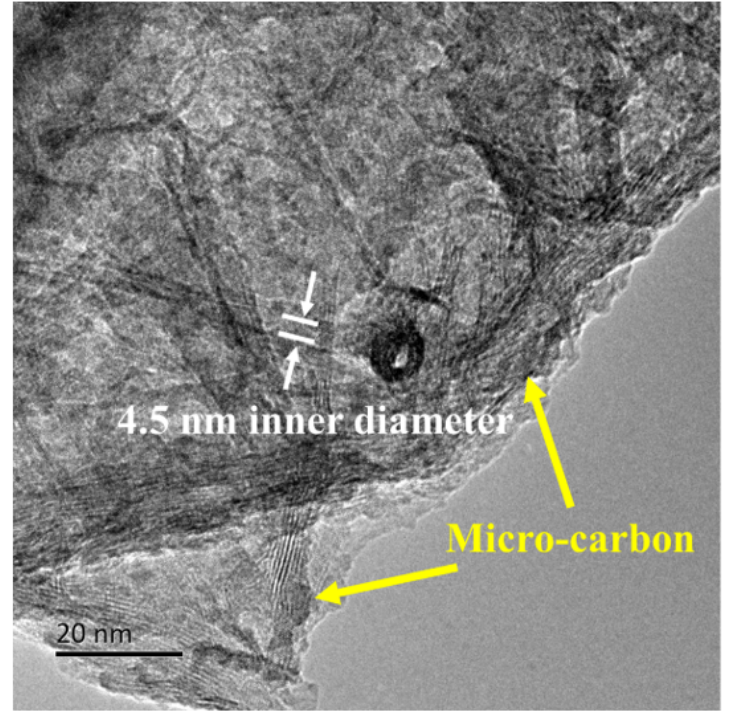

(b)

Figure 1. HRTEM (high-resolution transmission electron microscopy) images of TNTs@AC (activated charcoal supported titanate nanotubes), $50 \mathrm{~nm}$ (a) and $20 \mathrm{~nm}(\mathbf{b})$.

Table S2 (Supplementary Material) lists the salient physical parameters of TNTs, AC, and TNTs@AC. The BET (Brunauer-Emmett-Teller) surface area follows the order: AC $\left(566.1 \mathrm{~m}^{2} / \mathrm{g}\right)>\mathrm{TNTs}$ AC $\left(471.6 \mathrm{~m}^{2} / \mathrm{g}\right)>$ TNTs $\left(272.3 \mathrm{~m}^{2} / \mathrm{g}\right)$. However, the total pore volume for TNTs@AC $\left(0.52 \mathrm{~cm}^{3} / \mathrm{g}\right)$ is much lower than that of TNTs $\left(1.26 \mathrm{~cm}^{3} / \mathrm{g}\right)$, indicating that the micro-carbon may coat on the narrow throat of nanotubes [33]. In addition, the $\mathrm{pH}_{\mathrm{PZC}}$ values are derived as 6.8, 2.6, and 3.1 for AC, TNTs, and TNTs@AC [26], respectively.

\subsection{Adsorption Kinetics of E2 by TNTs@AC}

Figure 2 presents the adsorption kinetics of E2 by TNTs@AC. The removal efficiency of E2 reaches $99.8 \%$ and $91.5 \%$ for the initial E2 concentration of 0.5 and $1.0 \mathrm{mg} / \mathrm{L}$, respectively. For both cases, the adsorption equilibrium reaches within $360 \mathrm{~min}$.

The equilibrium E2 uptake $\left(q_{\mathrm{e}}, \mathrm{mg} / \mathrm{g}\right)$ and removal efficiency $(E, \%)$ were calculated as follows:

$$
\begin{gathered}
q_{e}=\frac{\left(C_{0}-C_{e}\right) V}{m} \\
E=\frac{\left(C_{0}-C_{e}\right)}{C_{0}} \times 100 \%
\end{gathered}
$$

where $C_{0}, C_{\mathrm{e}}, V$, and $m$ are the initial or equilibrium $\mathrm{E} 2$ concentrations $(\mathrm{mg} / \mathrm{L})$ in the aqueous phase, the solution volume $(\mathrm{L})$, and the materials mass, respectively.

Pseudo-first-order and pseudo-second-order kinetic models were able to interpret the experimental results [12,34-37], as described below:

Pseudo-first-order model:

$$
q_{t}=q_{e}-q_{e} \exp \left(-k_{1} t\right)
$$


Pseudo-second-order model:

$$
\frac{t}{q_{t}}=\frac{1}{k_{2} q_{e}^{2}}+\frac{t}{q_{e}}
$$

where $q_{t}$ and $q_{\mathrm{e}}$ are the E2 uptakes $(\mathrm{mg} / \mathrm{g})$ at time $t(\mathrm{~min})$ and equilibrium, respectively; $k_{1}\left(\mathrm{~min}^{-1}\right)$ and $k_{2}(\mathrm{~g} /(\mathrm{mg} \cdot \mathrm{min}))$ are the respective rate constants.

Table S3 (Supplementary Material) lists the fitted parameters of pseudo-first-order and pseudo-second-order kinetic models for E2 adsorption onto TNTs@AC. The pseudo-second-order model provides better-fitted results $\left(R^{2}>0.998\right)$. The corresponding calculated equilibrium adsorption capacity $\left(q_{\mathrm{e}, \mathrm{cal}}\right)$ for initial E2 concentration of 0.5 and $1.0 \mathrm{mg} / \mathrm{L}$ is 1.01 and $2.01 \mathrm{mg} / \mathrm{g}$, respectively, which is close to the experimental results $\left(q_{\mathrm{e}, \exp }=0.999\right.$ and $1.908 \mathrm{mg} / \mathrm{g}$, respectively).

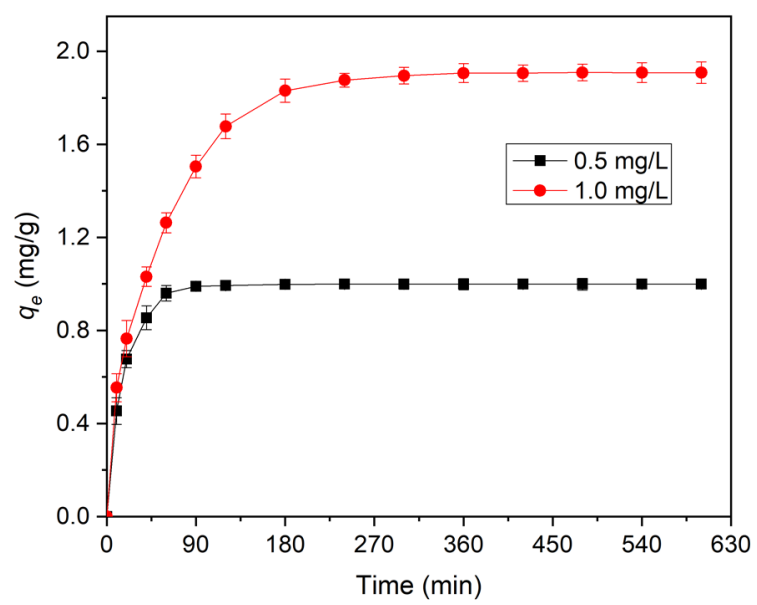

Figure 2. Adsorption kinetics of $17 \beta$-estradiol (E2) by TNTs@AC. (Initial E2 concentration = 0.5 or $1.0 \mathrm{mg} / \mathrm{L}$, material dosage $=0.5 \mathrm{~g} / \mathrm{L}, \mathrm{pH}=7.0 \pm 0.2$, temperature $=25 \pm 0.2{ }^{\circ} \mathrm{C}$ ).

\subsection{Adsorption Isotherms of E2 by Various Materials}

Figure 3a presents the adsorption isotherms of E2 by AC, TNTs, and TNTs@AC in the E2 concentration range from 0.1 to $1.5 \mathrm{mg} / \mathrm{L}$. It is clearly shown that TNTs@AC offer the highest adsorption E2 uptake. In addition, TNTs exhibit the negligent adsorption capacity for E2. The linear, Langmuir, Freundlich, and Dual-mode isotherm models were applied to simulate the experimental results as follows [26,38-40]:

Linear model:

$$
q_{e}=K_{d} C_{e}
$$

Langmuir model:

$$
q_{e}=\frac{b Q_{\max } C_{e}}{1+b C_{e}}
$$

Freundlich model:

$$
q_{e}=K_{F} C_{e}^{1 / n}
$$

Dual-mode model:

$$
q_{e}=\frac{b Q_{L} C_{e}}{1+b C_{e}}+K_{d} C_{e}
$$

where $q_{\mathrm{e}}$ and $C_{\mathrm{e}}$ : the solid and aqueous phase E2 concentrations $(\mathrm{mg} / \mathrm{g})$, respectively, at equilibrium, $K_{\mathrm{d}}$ : distribution coefficient $(\mathrm{L} / \mathrm{g}), K_{\mathrm{F}}$ : Freundlich capacity constant $\left(\mathrm{mg} / \mathrm{g} \cdot(\mathrm{L} / \mathrm{mg})^{1 / n}\right), n$ : Freundlich intensity constant, $b$ : Langmuir affinity coefficient $(\mathrm{L} / \mathrm{mg}) ; Q_{L}$ or $Q_{\max }$ : maximum Langmuir adsorption capacity $(\mathrm{mg} / \mathrm{g})$. 


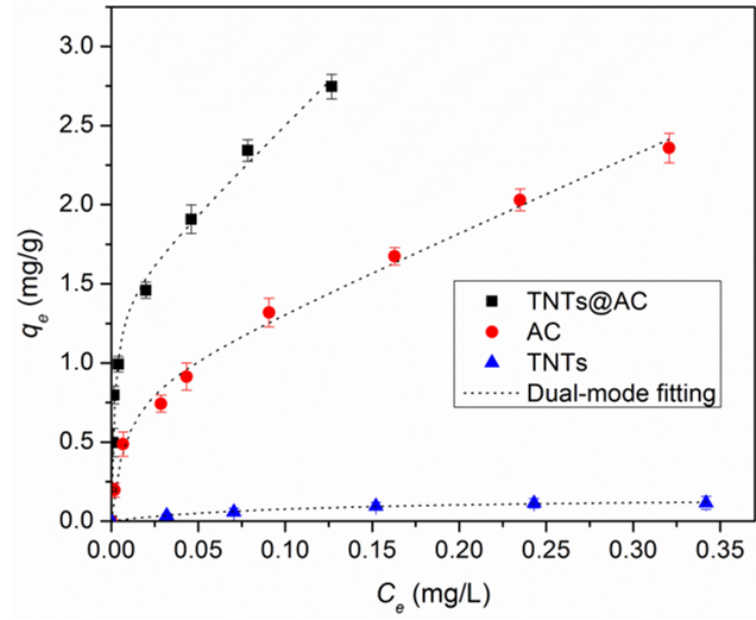

(a)

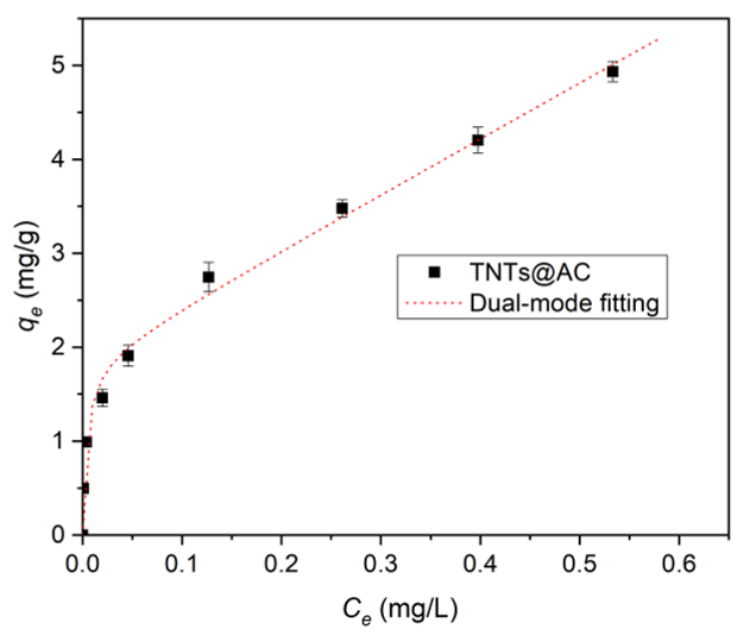

(b)

Figure 3. Adsorption isotherms of E2 by various materials (a); Adsorption isotherms of E2 at broad initial concentrations by TNTs@AC. (Initial E2 concentration $=0.1-1.5 \mathrm{mg} / \mathrm{L}$ (a) and 0.25-3.0 mg/L (b), material dosage $=0.5 \mathrm{~g} / \mathrm{L}$, temperature $=25 \pm 0.2{ }^{\circ} \mathrm{C}$, volume of solution $=40 \mathrm{~mL}$, solution $\mathrm{pH}=7.0 \pm 0.2$ ). Symbols: experimental data; Dash-lines: dual-model fittings.

Table 1 lists the fitted parameters of various isotherm models for E2 adsorption onto different materials. The dual-model isotherm model offers the best-fitted results $\left(R^{2} \geq 0.995\right)$ than the other three classic isotherm models. The maximum adsorption capacity $\left(Q_{\mathrm{L}}\right)$ of three materials follows the order: TNTs@AC $(1.44 \mathrm{mg} / \mathrm{g})>$ AC $(0.89 \mathrm{mg} / \mathrm{g})>$ TNTs $(0.16 \mathrm{mg} / \mathrm{g})$, which agree with the BET surface area (Table S2, Supplementary Material). For AC, the hydrophobic effect and $\pi-\pi$ interaction are the dominant mechanisms for E2 adsorption [12]. The strong hydrophobic E2 molecule [5] is difficult to be adsorbed onto TNTs, and thus the low E2 uptake is attributed to the electrostatic attraction between neutral E2 molecules and negatively charged TNTs (Table S2, Supplementary Material). However, for TNTs@AC composites, not only AC surface was modified by TNTs, but TNTs were attached by micro-carbon. Thus, the higher uptake of E2 by TNTs@AC than neat AC and TNTs was reached via the hydrophobic and $\pi-\pi$ interactions contributed by modified AC and capillary condensation from the micro-carbon-modified TNTs $[15,26]$.

Table 1. Parameters of isotherm models for E2 $(0.1-1.5 \mathrm{mg} / \mathrm{L})$ adsorption onto various materials.

\begin{tabular}{ccccc}
\hline \multirow{2}{*}{ Models } & Parameters & \multicolumn{3}{c}{ Materials } \\
\cline { 3 - 5 } & & TNTs@AC & AC & TNTs \\
\hline \multirow{2}{*}{ Liner model } & $K_{\mathrm{d}}(\mathrm{L} / \mathrm{g})$ & 26.46 & 8.64 & 0.426 \\
& $R^{2}$ & 0.542 & 0.762 & 0.697 \\
Langmuir model & $Q_{\max (\mathrm{mg} / \mathrm{g})}$ & 2.78 & 2.57 & 0.16 \\
& $b(\mathrm{~L} / \mathrm{mg})$ & 102.89 & 17.20 & 9.60 \\
& $R^{2}$ & 0.977 & 0.949 & 0.991 \\
Freundlich model & $K_{F}$ & 6.82 & 3.94 & 0.23 \\
& $\left(\mathrm{mg} / \mathrm{g} \cdot(\mathrm{L} / \mathrm{mg})^{1 / n}\right)$ & 2.53 & 2.18 & 1.95 \\
& $n$ & 0.913 & 0.989 & 0.970 \\
& $R^{2}$ & 10.84 & 4.83 & 0.006 \\
Dual-mode model & $K_{\mathrm{d}}(\mathrm{L} / \mathrm{g})$ & 1.44 & 0.89 & 0.16 \\
& $Q_{\mathrm{L}}(\mathrm{mg} / \mathrm{g})$ & 511.95 & 126.18 & 9.49 \\
& $b(\mathrm{~L} / \mathrm{mg})$ & 0.995 & 0.996 & 0.995 \\
\hline
\end{tabular}


To further explore the adsorption mechanism of E2 onto TNTs@AC via the capillary condensation, the initial E2 concentration is increased from 0.25 to $3.0 \mathrm{mg} / \mathrm{L}$, as shown in Figure $3 \mathrm{~b}$. The fitted parameters by various isotherm models are listed in Table 2. It is evidently showed that there is a two-stage isotherm profile, i.e., Langmuir adsorption at lower $C_{e}(<0.06 \mathrm{mg} / \mathrm{L})$ following the linear uptake at higher $C_{e}$, which is similar with the observation by Liu et al. [26], considering the dual-mode adsorption, i.e., Langmuir-type adsorption and capillary condensation. In addition, the maximum adsorption capacity $\left(Q_{\mathrm{L}}\right)$ is increased to $1.87 \mathrm{mg} / \mathrm{g}$ at high E2 concentration (Table 2) than $1.44 \mathrm{mg} / \mathrm{g}$ at low E2 concentration (Figure 3a), indicating TNTs@AC could adsorb E2 not only by surface hydrophobic and $\pi-\pi$ interactions but also by the capillary condensation. The detailed E2 adsorption mechanism onto TNTs@AC is discussed in Section 3.5.

Table 2. Parameters of isotherm models for E2 (0.25-3.0 mg/L) adsorption onto TNTs@AC.

\begin{tabular}{ccc}
\hline \multirow{2}{*}{ Models } & Parameters & Materials \\
\cline { 3 - 3 } & & TNTs@AC \\
\hline \multirow{2}{*}{ Liner model } & $K_{\mathrm{d}}(\mathrm{L} / \mathrm{g})$ & 10.729 \\
& $R^{2}$ & 0.669 \\
Langmuir model & $Q_{\max }(\mathrm{mg} / \mathrm{g})$ & 4.82 \\
& $b(\mathrm{~L} / \mathrm{mg})$ & 23.58 \\
& $R^{2}$ & 0.958 \\
Freundlich model & $K_{\mathrm{F}}\left(\mathrm{mg} / \mathrm{g} \cdot(\mathrm{L} / \mathrm{mg})^{1 / n}\right)$ & 2.87 \\
& $n$ & 5.79 \\
& $R^{2}$ & 0.991 \\
Dual-mode model & $K_{\mathrm{d}}(\mathrm{L} / \mathrm{g})$ & 5.91 \\
& $Q_{\mathrm{L}}(\mathrm{mg} / \mathrm{g})$ & 1.87 \\
& $b(\mathrm{~L} / \mathrm{mg})$ & 239.36 \\
& $R^{2}$ & 0.995 \\
\hline
\end{tabular}

\subsection{Photoregeneration of TNTs@AC}

Figure 4 shows that the photo-degradation of adsorbed E2 by AC could be negligible $(<10 \%)$, and the mass loss could be attributed to the extraction method. However, the adsorbed E2 on TNTs@AC is significantly degraded, i.e., 99.8\% and 98.7\%, under UV irradiation within 120 min for initial E2 concentration of 0.5 and $1.0 \mathrm{mg} / \mathrm{L}$, respectively, indicating the TNTs@AC composites exhibited the excellent photocatalytic activity. The details on the E2 degradation mechanism and enhanced photocatalysis for TNTs@AC are elucidated in Section 3.5.

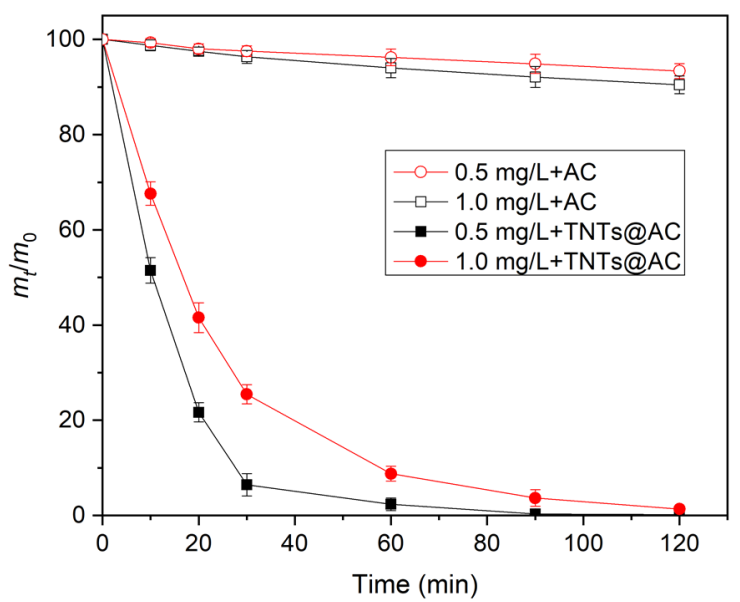

Figure 4. Photo-degradation kinetics of adsorbed E2 by activated charcoal (AC) and TNTs@AC. (Initial E2 concentration $=0.5$ or $1.0 \mathrm{mg} / \mathrm{L}$, material dosage $=0.5 \mathrm{~g} / \mathrm{L}$, temperature $=25 \pm 0.2{ }^{\circ} \mathrm{C}$, volume of solution $=40 \mathrm{~mL}$, solution $\mathrm{pH}=7.0 \pm 0.2$ ). 


\subsection{Removal Mechanism of E2 by TNTs@AC}

Figure 5 elucidates the removal, i.e., adsorption and photo-degradation, mechanisms of E2 by TNTs@AC. For the E2 uptake onto TNTs@AC, both TNTs and AC play significant roles in the adsorption. First, E2 molecules have high hydrophobicity, i.e., $K_{\mathrm{owv}}=4.01$ [5], resulting in E2 that is favorable to attach on the AC surface via the hydrophobic and $\pi-\pi$ interactions $[12,41]$. Second, based on the theoretical calculation of electrostatic potential (ESP) energy, the red sides have the highest ESP value to $61 \mathrm{kcal} / \mathrm{mol}$ (Figure 6a), which can be attracted to the negatively charged TNTs via the weak electrostatic attraction. Third, from the Figure $6 \mathrm{~b}$, the three dimensions of E2 molecules are 7.87, 14.43 , and $7.64 \AA$, which is much smaller than the inner diameter of TNTs, i.e., $4.5 \mathrm{~nm}$ [42] (Figure 1), indicating the E2 molecules can enter the tubular structure, leading to the capillary condensation by micro-carbon-modified TNTs (Figure 3). Thus, the adsorption capacity of E2 was significantly enhanced for TNTs@AC (Figure 3).

Adsorption

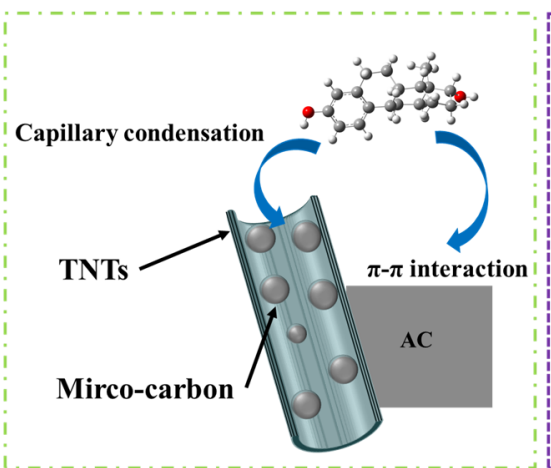

Photodegradation/Regeneration

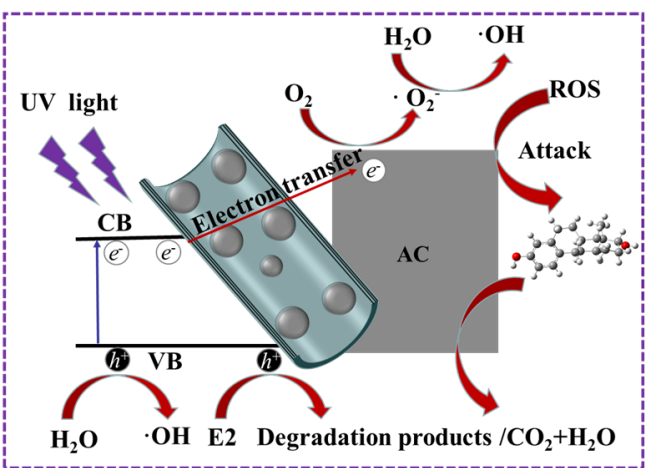

Figure 5. Schematic of the removal mechanism of E2 by TNTs@AC.

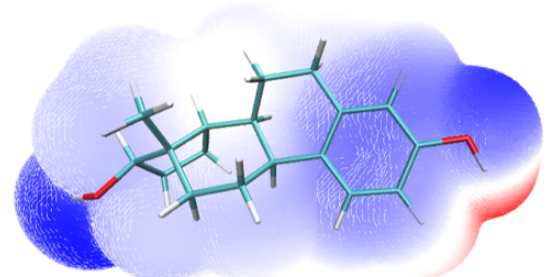

(a)

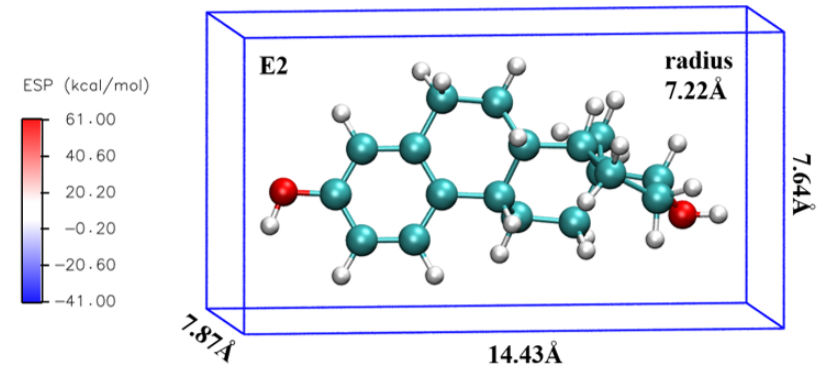

(b)

Figure 6. Electrostatic potential (ESP) energy (a); Three dimensions of E2 after density functional theory (DFT) optimization (b).

For the photo-degradation of adsorbed E2 by TNTs@AC, under the UV irradiation, TNTs can generate the valence band (VB) and conduction band (CB) (Figure 5). The photo-induced electrons $\left(e_{T i}{ }^{-}\right)$and holes $\left(h_{T i}{ }^{+}\right)$are produced in $\mathrm{CB}$ and $\mathrm{VB}$, respectively (Equation (9)). Then, the generated holes can directly oxidize the water or hydroxide ion to produce hydroxyl radical $(\bullet \mathrm{OH})$ (Equations $(10)$ and (11)). Meanwhile, upon the surface modification, the coated micro-carbon and grafted AC can act as the new electron acceptor to transfer photo-generated electrons to $\mathrm{AC} /$ micro-carbon phase, then inhibit the electron-hole recombination (Equation (12)). The oxygen molecule will obtain the electron from AC or micro-carbon phase to produce the superoxide radical $\left(\bullet \mathrm{O}_{2}{ }^{-}\right)$(Equation (13)). In addition, $\bullet \mathrm{OH}$ also can be derived from $\bullet \mathrm{O}_{2}{ }^{-}$, based on Equation 14. The generated radicals and 
$h^{+}$are charge of E2 degradation (Equations (15) and (16)), which perform the photo-regeneration for TNTs@AC under UV irradiation.

$$
\begin{gathered}
\mathrm{TNTs} @ \mathrm{AC}+h v \rightarrow \mathrm{TiO}_{2}\left(e_{T i}^{-}-h_{T i}{ }^{+}\right) \\
\mathrm{H}_{2} \mathrm{O}+h^{+} \rightarrow \bullet \mathrm{OH}+\mathrm{H}^{+} \\
\mathrm{OH}^{-}+h^{+} \rightarrow \bullet \mathrm{OH} \\
\mathrm{AC}+e_{T i}^{-} \rightarrow \mathrm{AC}-e_{T i}^{-}(\text {electron transfer }) \\
\mathrm{O}_{2}+e^{-} \rightarrow \bullet \mathrm{O}_{2}{ }^{-} \\
\bullet \mathrm{O}_{2}{ }^{-}+2 e^{-}+2 \mathrm{H}^{+} \rightarrow \bullet \mathrm{OH}+\mathrm{OH}^{-} \\
\mathrm{E} 2+\mathrm{ROS} \rightarrow \text { intermediates } \rightarrow \text { products }+\mathrm{CO}_{2} \\
\mathrm{E} 2+h^{+} \rightarrow \text { intermediates } \rightarrow \text { products }+\mathrm{CO}_{2}
\end{gathered}
$$

Figure 7 proposes the E2 degradation pathway by TNTs@AC under UV irradiation. The main intermediates (IM) are detected as IM1 $(\mathrm{m} / \mathrm{z} 287)$ and IM2 $(\mathrm{m} / \mathrm{z} 335)$ via the hydroxyl radical attack $(\bullet \mathrm{OH})$, which is consistent with another report [5]. Then, ring-open products via the deeper oxidation occur [5]. Carbon oxide and water subsequently undergo further mineralization.
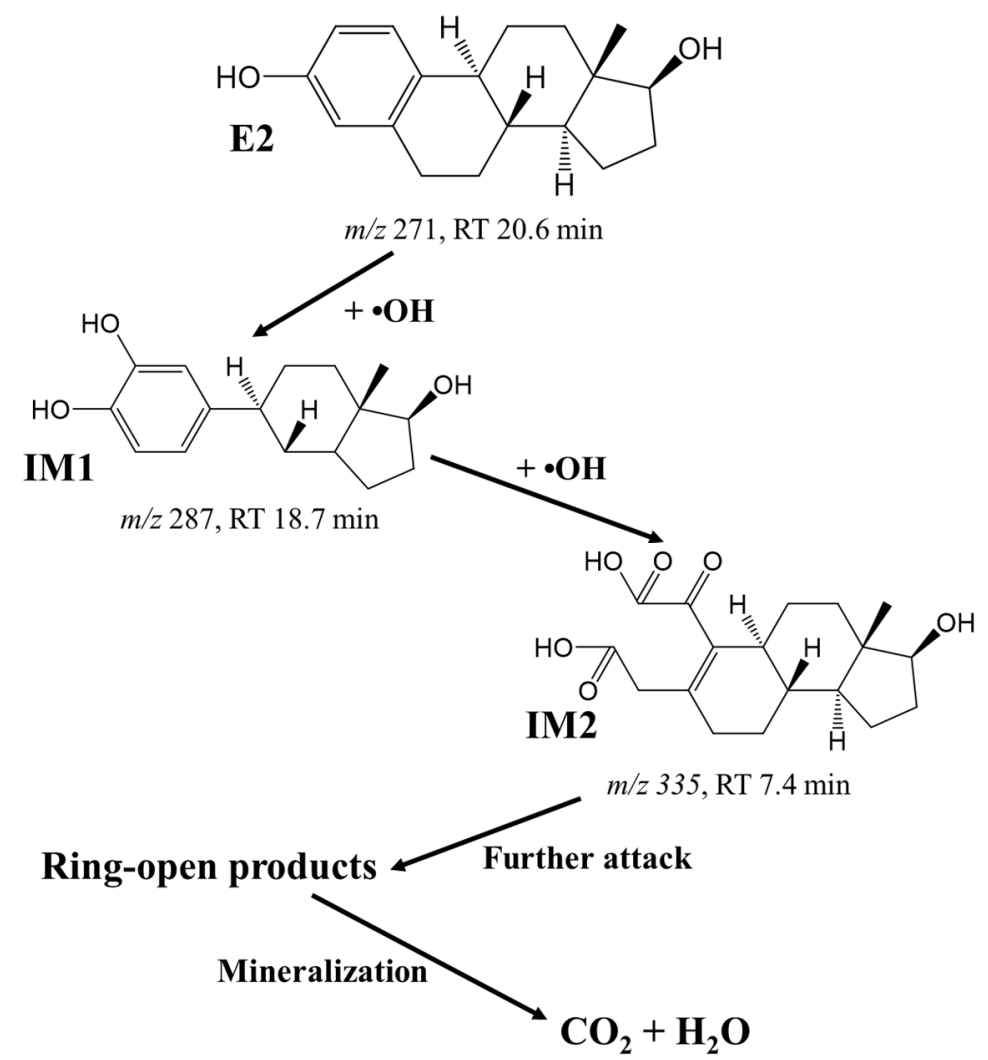

Figure 7. Photo-degradation pathway of adsorbed E2 by AC and TNTs@AC. (Initial E2 concentration $=0.5$ or $1.0 \mathrm{mg} / \mathrm{L}$, material dosage $=0.5 \mathrm{~g} / \mathrm{L}$, temperature $=25 \pm 0.2{ }^{\circ} \mathrm{C}$, volume of solution $=40 \mathrm{~mL}$, solution $\mathrm{pH}=7.0 \pm 0.2$ ).

\section{Conclusions}

In this study, low-cost activated charcoal supported titanate nanotubes material via the one-step facial hydrothermal method was prepared to remove E2 through initial adsorption and subsequent photo-degradation. TNTs@AC exhibited good adsorption capacity for E2 (1.44 mg/g at low E2 
concentration and $1.87 \mathrm{mg} / \mathrm{g}$ at high E2 concentration) based on the dual-mode model fitting due to the modification for both AC and TNTs and simultaneously performed excellent photocatalytic degradation under UV irradiation (99.8\% degradation of adsorbed E2 within $2 \mathrm{~h}$ ). HRTEM images indicated that the formed titanate nanotubes would be grafted onto the AC surface, and the micro-carbon could modify the tubular structure of TNTs, which build the well-designed structure to facilitate the adsorption and electron transfer. High E2 uptake was achieved through hydrophobic effect, $\pi-\pi$ interaction, and capillary condensation. In addition, based on the DFT theoretical calculation, the benzene ring side of the E2 molecule had the highest ESP value as $61 \mathrm{kcal} / \mathrm{mol}$, which favored attaching onto materials. The three dimensions of E2 molecules, i.e., 7.87, 14.43, and $7.64 \AA$, less than the inner diameter of TNTs, i.e., $4.5 \mathrm{~nm}$, guaranteeing the occurrence of the capillary condensation. Moreover, the coated micro-carbon and grafted AC can act as the new electron acceptor to transfer photo-generated electrons to AC/micro-carbon phase, then inhibit the electron-hole recombination. Therefore, TNTs@AC is a promising material for E2 removal and could provide the potential application via easy regeneration.

Supplementary Materials: The following are available online at http://www.mdpi.com/2073-4441/12/8/2121/s1, Figure S1. Optimized geometry coordinates and structure of E2, Table S1. Cartesian coordinates (Angstroms), Table S2. Salient physical parameters of TNTs, AC, and TNTs@AC, Table S3. Parameters of pseudo-first-order and pseudo-second-order kinetic models for E2 adsorption onto TNTs@AC.

Author Contributions: Conceptualization, W.L. and H.J.; methodology, W.L. and H.J.; software, T.H.; formal analysis, H.J.; investigation, T.H. and W.L.; data curation, H.J.; writing-original draft preparation, H.J.; writing-review and editing, B.P., W.L., and H.J.; visualization, T.H.; supervision, H.J.; funding acquisition, W.L. All authors have read and agreed to the published version of the manuscript.

Funding: This research was funded by the National Natural Science Foundation of China (NSFC) (No. 21906001 and No. 51925901), by the Beijing Nova Program (Z19111000110000), and the Opening Foundation of Ministry of Education Key Laboratory of Pollution Processes and Environmental Criteria (201901). China Postdoctoral Science Foundation (No. 2020M670049) is greatly acknowledged.

Conflicts of Interest: The authors declare no conflict of interest.

\section{References}

1. Ejhed, H.; Fång, J.; Hansen, K.; Graae, L.; Rahmberg, M.; Magnér, J.; Dorgeloh, E.; Płaza, G.A. The effect of hydraulic retention time in onsite wastewater treatment and removal of pharmaceuticals, hormones and phenolic utility substances. Sci. Total Environ. 2018, 618, 250-261. [CrossRef] [PubMed]

2. Aris, A.Z.; Shamsuddin, A.S.; Praveena, S.M. Occurrence of $17 \alpha$-ethynylestradiol (EE2) in the environment and effect on exposed biota: A review. Environ. Int. 2014, 69, 104-119. [CrossRef] [PubMed]

3. Jiang, L.; Liu, Y.; Liu, S.; Hu, X.; Zeng, G.; Hu, X.; Liu, S.; Liu, S.; Huang, B.; Li, M. Fabrication of $\beta$-cyclodextrin/poly (l-glutamic acid) supported magnetic graphene oxide and its adsorption behavior for 17ß-estradiol. Chem. Eng. J. 2017, 308, 597-605. [CrossRef]

4. Shyu, C.; Cavileer, T.D.; Nagler, J.J.; Ytreberg, F.M. Computational estimation of rainbow trout estrogen receptor binding affinities for environmental estrogens. Toxicol. Appl. Pharmacol. 2011, 250, 322-326. [CrossRef] [PubMed]

5. Du, P.; Chang, J.; Zhao, H.; Liu, W.; Dang, C.; Tong, M.; Ni, J.; Zhang, B. Sea-Buckthorn-Like MnO2 Decorated Titanate Nanotubes with Oxidation Property and Photocatalytic Activity for Enhanced Degradation of 17ß-Estradiol under Solar Light. ACS Appl. Energy Mater. 2018, 1, 2123-2133. [CrossRef]

6. Yin, Z.; Liu, Y.; Liu, S.; Jiang, L.; Tan, X.; Zeng, G.; Li, M.; Liu, S.; Tian, S.; Fang, Y. Activated magnetic biochar by one-step synthesis: Enhanced adsorption and coadsorption for $17 \beta$-estradiol and copper. Sci. Total Environ. 2018, 639, 1530-1542. [CrossRef]

7. Yoon, Y.; Westerhoff, P.; Snyder, S.A.; Wert, E.C. Nanofiltration and ultrafiltration of endocrine disrupting compounds, pharmaceuticals and personal care products. J. Membr. Sci. 2006, 270, 88-100. [CrossRef]

8. Shon, H.; Vigneswaran, S.; Snyder, S.A. Effluent Organic Matter (EfOM) in Wastewater: Constituents, Effects, and Treatment. Crit. Rev. Environ. Sci. Technol. 2006, 36, 327-374. [CrossRef]

9. Leech, D.M.; Snyder, M.T.; Wetzel, R.G. Natural organic matter and sunlight accelerate the degradation of 17ß-estradiol in water. Sci. Total Environ. 2009, 407, 2087-2092. [CrossRef] 
10. Cai, Z.; Dwivedi, A.D.; Lee, W.-N.; Zhao, X.; Liu, W.; Sillanpää, M.; Zhao, D.; Huang, C.-H.; Fu, J. Application of nanotechnologies for removing pharmaceutically active compounds from water: Development and future trends. Environ. Sci. Nano 2018, 5, 27-47. [CrossRef]

11. Zhang, Y.; Zhou, J.L. Removal of estrone and $17 \beta$-estradiol from water by adsorption. Water Res. 2005, 39, 3991-4003. [CrossRef] [PubMed]

12. Ji, H.; Xie, W.; Liu, W.; Liu, X.; Zhao, D. Sorption of dispersed petroleum hydrocarbons by activated charcoals: Effects of oil dispersants. Environ. Pollut. 2019, 256, 113416. [CrossRef] [PubMed]

13. Jiang, L.; Liu, Y.; Zeng, G.; Liu, S.; Hu, X.; Zhou, L.; Tan, X.; Liu, N.; Li, M.; Wen, J. Adsorption of estrogen contaminants (17 $\beta$-estradiol and $17 \alpha$-ethynylestradiol) by graphene nanosheets from water: Effects of graphene characteristics and solution chemistry. Chem. Eng. J. 2018, 339, 296-302. [CrossRef]

14. Jung, C.; Son, A.; Her, N.; Zoh, K.-D.; Cho, J.; Yoon, Y. Removal of endocrine disrupting compounds, pharmaceuticals, and personal care products in water using carbon nanotubes: A review. J. Ind. Eng. Chem. 2015, 27, 1-11. [CrossRef]

15. Dang, C.; Sun, F.; Jiang, H.; Huang, T.; Liu, W.; Chen, X.; Ji, H. Pre-accumulation and in-situ destruction of diclofenac by a photo-regenerable activated carbon fiber supported titanate nanotubes composite material: Intermediates, DFT calculation, and ecotoxicity. J. Hazard. Mater. 2020, 400, 123225. [CrossRef]

16. Liu, W.; Wang, T.; Borthwick, A.G.; Wang, Y.; Yin, X.; Li, X.; Ni, J. Adsorption of $\mathrm{Pb}^{2+}, \mathrm{Cd}^{2+}, \mathrm{Cu}^{2+}$ and $\mathrm{Cr}^{3+}$ onto titanate nanotubes: Competition and effect of inorganic ions. Sci. Total Environ. 2013, 456, 171-180. [CrossRef]

17. Sun, W.; Li, M.; Zhang, W.; Wei, J.; Chen, B.; Wang, C. Sediments inhibit adsorption of $17 \beta$-estradiol and $17 \alpha$-ethinylestradiol to carbon nanotubes and graphene oxide. Environ. Sci. Nano 2017, 4, 1900-1910. [CrossRef]

18. Liu, X.; Wang, M.; Zhang, S.; Pan, B. Application potential of carbon nanotubes in water treatment: A review. J. Environ. Sci. 2013, 25, 1263-1280. [CrossRef]

19. Zhang, Y.; Xu, J.; Mei, J.; Sarina, S.; Wu, Z.; Liao, T.; Yan, C.; Sun, Z. Strongly interfacial-coupled 2D-2D $\mathrm{TiO} 2 / \mathrm{g}-\mathrm{C} 3 \mathrm{~N} 4$ heterostructure for enhanced visible-light induced synthesis and conversion. J. Hazard. Mater. 2020, 394, 122529. [CrossRef]

20. Trellu, C.; Mousset, E.; Pechaud, Y.; Huguenot, D.; Van Hullebusch, E.D.; Esposito, G.; Oturan, N. Removal of hydrophobic organic pollutants from soil washing/flushing solutions: A critical review. J. Hazard. Mater. 2016, 306, 149-174. [CrossRef]

21. Wang, J.; Zhuan, R. Degradation of antibiotics by advanced oxidation processes: An overview. Sci. Total Environ. 2019, 701, 135023. [CrossRef]

22. Liu, W.; Zhao, X.; Borthwick, A.G.L.; Wang, Y.; Ni, J. Dual-Enhanced Photocatalytic Activity of Fe-Deposited Titanate Nanotubes Used for Simultaneous Removal of As(III) and As(V). ACS Appl. Mater. Interfaces 2015, 7, 19726-19735. [CrossRef] [PubMed]

23. Zheng, T.; Wang, T.; Ma, R.; Liu, W.; Cui, F.; Sun, W. Influences of isolated fractions of natural organic matter on adsorption of $\mathrm{Cu}$ (II) by titanate nanotubes. Sci. Total Environ. 2019, 650, 1412-1418. [CrossRef] [PubMed]

24. Cheng, K.; Cai, Z.; Fu, J.; Sun, X.; Sun, W.; Chen, L.; Zhang, D.; Liu, W. Synergistic adsorption of Cu(II) and photocatalytic degradation of phenanthrene by a jaboticaba-like TiO2/titanate nanotube composite: An experimental and theoretical study. Chem. Eng. J. 2019, 358, 1155-1165. [CrossRef]

25. Lin, Y.; Ma, J.; Liu, W.; Li, Z.; He, K. Efficient removal of dyes from dyeing wastewater by powder activated charcoal/titanate nanotube nanocomposites: Adsorption and photoregeneration. Environ. Sci. Pollut. Res. 2019, 26, 10263-10273. [CrossRef] [PubMed]

26. Liu, W.; Cai, Z.; Zhao, X.; Wang, T.; Li, F.; Zhao, D. High-Capacity and Photoregenerable Composite Material for Efficient Adsorption and Degradation of Phenanthrene in Water. Environ. Sci. Technol. 2016, 50, 11174-11183. [CrossRef] [PubMed]

27. Frisch, M.J.; Trucks, G.W.; Schlegel, H.B.; Scuseria, G.E.; Robb, M.A.; Cheeseman, J.R.; Scalmani, G.; Barone, V.; Petersson, G.A.; Nakatsuji, H.; et al. Gaussian 16 Rev. C.01. Available online: https://gaussian.com/citation/ (accessed on 22 July 2020).

28. Ji, H.; Du, P.; Zhao, D.; Li, S.; Sun, F.; Duin, E.C.; Liu, W. 2D/1D graphitic carbon nitride/titanate nanotubes heterostructure for efficient photocatalysis of sulfamethazine under solar light: Catalytic "hot spots" at the rutile-anatase-titanate interfaces. Appl. Catal. B Environ. 2020, 263, 118357. [CrossRef] 
29. Ma, M.; Chen, L.; Zhao, J.; Liu, W.; Ji, H. Efficient activation of peroxymonosulfate by hollow cobalt hydroxide for degradation of ibuprofen and theoretical study. Chin. Chem. Lett. 2019, 30, 2191-2195. [CrossRef]

30. Liu, X.; Ji, H.; Li, S.; Liu, W. Graphene modified anatase/titanate nanosheets with enhanced photocatalytic activity for efficient degradation of sulfamethazine under simulated solar light. Chemosphere 2019, 233, 198-206. [CrossRef]

31. Manzetti, S.; Lu, T. The geometry and electronic structure of Aristolochic acid: Possible implications for a frozen resonance. J. Phys. Org. Chem. 2013, 26, 473-483. [CrossRef]

32. Humphrey, W.; Dalke, A.; Schulten, K. VMD: Visual molecular dynamics. J. Mol. Graph. 1996, 14, 33-38. [CrossRef]

33. Ma, J.; Li, F.; Qian, T.; Liu, H.; Liu, W.; Zhao, D. Natural organic matter resistant powder activated charcoal supported titanate nanotubes for adsorption of $\mathrm{Pb}(\mathrm{II})$. Chem. Eng. J. 2017, 315. [CrossRef]

34. Ho, Y.; McKay, G. Sorption of dye from aqueous solution by peat. Chem. Eng. J. 1998, 70, 115-124. [CrossRef]

35. Ji, H.; Zhu, Y.; Duan, J.; Liu, W.; Zhao, D. Reductive immobilization and long-term remobilization of radioactive pertechnetate using bio-macromolecules stabilized zero valent iron nanoparticles. Chin. Chem. Lett. 2019, 30, 2163-2168. [CrossRef]

36. Ji, H.; Zhu, Y.; Liu, W.; Bozack, M.J.; Qian, T.; Zhao, D. Sequestration of pertechnetate using carboxymethyl cellulose stabilized FeS nanoparticles: Effectiveness and mechanisms. Colloids Surf. A Physicochem. Eng. Asp. 2019, 561, 373-380. [CrossRef]

37. Ji, H.; Gong, Y.; Duan, J.; Zhao, D.; Liu, W. Degradation of petroleum hydrocarbons in seawater by simulated surface-level atmospheric ozone: Reaction kinetics and effect of oil dispersant. Mar. Pollut. Bull. 2018, 135, 427-440. [CrossRef]

38. Langmuir, I. The adsorption of gases on plane surfaces of glass, mica and platinum. J. Am. Chem. Soc. 1918, 40,1361-1403. [CrossRef]

39. Freundlich, H. Über die adsorption in lösungen. Z. Phys. Chem. 1906, 57, 385-470. [CrossRef]

40. Zhao, D.; Pignatello, J.J.; White, J.C.; Braida, W.; Ferrandino, F. Dual-mode modeling of competitive and concentration-dependent sorption and desorption kinetics of polycyclic aromatic hydrocarbons in soils. Water Resour. Res. 2001, 37, 2205-2212. [CrossRef]

41. Liao, Z.; Nguyen, M.N.; Wan, G.; Xie, J.; Ni, L.; Qi, J.; Li, J.; Schafer, A.I. Low pressure operated ultrafiltration membrane with integration of hollow mesoporous carbon nanospheres for effective removal of micropollutants. J. Hazard. Mater. 2020, 397, 122779. [CrossRef]

42. Liu, W.; Zhao, X.; Wang, T.; Zhao, D.; Ni, J. Adsorption of U(VI) by multilayer titanate nanotubes: Effects of inorganic cations, carbonate and natural organic matter. Chem. Eng. J. 2016, 286, 427-435. [CrossRef] 